\title{
Grao de desenvolvemento do turismo rural en Galicia: a oferta complementaria como clave do éxito
}

\author{
Andrea Cabaleiro Besada / Noelia Araújo Vila*b / José Antonio Fraiz Breab \\ aViajes Airbus \\ bUniversidade de Vigo - Facultade de Ciencias Empresariais e Turismo de Ourense
}

Recibido: 20 de marzo de 2018 / Aceptado: 26 de abril de 2019

\begin{abstract}
Resumo
O turismo rural é un modelo turístico, afastado da masificación, que se desenvolve no ámbito rural. 0 obxectivo desta investigación céntrase en determinar cal é o grao de desenvolvemento do turismo rural en Galicia, así como matizar cal é a oferta complementaria a este tipo de turismo máis solicitada, buscando sinerxías con outras empresas dos medios rurais. Para iso establécese un marco teórico sobre o que traballar e, posteriormente, a realización de entrevistas en profundidade a expertos do sector e a propietarios ou xestores de casas rurais nesta Comunidade Autónoma. Entre as principais conclusións podemos sinalar que practicamente calquera tipo de actividade complementaria é compatible con este tipo de turismo coa condición de que conste de axudas e accións adecuadas.
\end{abstract}

\section{Palabras clave}

Turismo rural / Galicia / Desenvolvemento / Tendencias / Oferta / Demanda.

\section{Degree of development of rural tourism in Galicia: The complementary offer as the key to success}

\begin{abstract}
Rural tourism is a model far away from mass tourism that takes place in rural areas. The main objective of this investigation focuses on determining the level of development of rural tourism in Galicia and explaining the most sought-after complementary offer to this kind of tourism, seeking synergies with other companies in rural areas. For this, a theoretical framework on which to work must be established,then in-depth interviews with industry experts and owners or managers of rural houses of this region should be conducted. Among the main conclusions is that virtually any type of complementary activity is compatible with this type of tourism, as long as itis backed by support and appropriate actions.
\end{abstract}

\section{Keywords}

Rural tourism / Galicia / Development / Trends / Offer / Demand.

JEL Codes: L83, Z32.

\section{Introdución}

Desde as súas orixes, en España o turismo caracterizouse por seguir un modelo turístico convencional de sol e praia, vinculado á construción de grandes complexos urbanísticos e á masificación de territorios, xerando un grande impacto ambiental (Martínez e Ramón, 2011).

En resposta a esta problemática, xorden distintos tipos de turismos alternativos ao modelo turístico tradicional. Entre eles atópase o turismo rural, que se sitúa como un turismo baseado na sustentabilidade e no respecto ao medio ambiente. Da mesma maneira, os turistas tamén foron evolucionando, e

* Correspondencia autora: naraujo@uvigo.es 
na actualidade móstranse cada vez máis interesados en involucrarse coa contorna e en vivir novas experiencias. Por ambos os dous motivos, o turismo rural está a verse favorecido, e por iso está a experimentar un importante crecemento nestes momentos (Peñalver, 2004).

Co presente estudo preténdese chegar a un maior coñecemento sobre o grao de desenvolvemento do turismo rural en España, prestándolle especial atención á Comunidade Autónoma de Galicia. A través desta investigación búscase detectar as oportunidades das que se pode valer este territorio para potenciar este tipo de turismo e propor posibles melloras, tomando como referencia as principais empresas de turismo rural desta área xeográfica, así como actividades complementarias que poidan axudar a favorecer este tipo de turismo.

Co fin de alcanzar os propósitos mencionados anteriormente realizarase, en primeiro lugar, unha revisión literaria do dito concepto, e mais da caracterización da oferta e da demanda en España. Unha vez realizada esta parte, procederase á recollida de datos primarios en Galicia a través da técnica cualitativa da entrevista en profundidade, co fin de obter un resultado capaz de proporcionarnos a información proposta desde un principio. A continuación, exporanse os principais resultados desas entrevistas e, finalmente, as principais conclusións extraídas deste estudo. Entre elas, hai que mencionar o longo percorrido que é necesario realizar para paliar o déficit na organización, formación e accións axustadas á demanda existente e futura do turismo rural en Galicia. Tamén, centrándonos na oferta complementaria -subobxectivo deste traballo-, conclúese que non é necesaria unha oferta complementaria específica ou determinada para o turismo rural, senón que calquera tipo de actividade complementaria é compatible con este tipo de turismo coa condición de que conste de axudas e accións adecuadas.

\section{Contextualización do turismo rural}

O turismo rural en España tivo un impacto positivo no últimos dez anos. Este crecemento débese ao interese mostrado pola fuxida dos medios urbanos, a procura dun estilo de vida máis saudable e relacionarse coa contorna natural e cos valores ou costumes da cultura local, materializándose o descrito no medio rural (Pulido e Cárdenas, 2011). Estas afirmacións foron sustentadas por García Henche (2006), quen indica que as causas para que se dea un turismo rural son as seguintes: que haxa unha maior concienciación ambiental, que se cree unha cultura neste sentido (é por iso polo que moita demanda prefire destinos non tan turísticos pero con maior calidade ambiental); que cada vez a xente aproveite máis os seus días de lecer viaxando tamén nas pontes e nas fins de semana; ou que se considere que o turismo rural pode favorecer o desenvolvemento económico de áreas deprimidas no espazo rural. Neste sentido, existe un apoio por parte da Unión Europea para o desenvolvemento do turismo rural.

Diversos autores e expertos no sector da industria turística e relacionados con ela (Brunet e Alarcón, 2008; Campón, Baptista e Hernández, 2009; Cebrián e García, 2009; Chicharro e Galve, 2009; Correia e Miranda, 2006; Crosby [Coord.], 2009; De la Calle e García, 2006; Flores e Barroso, 2011; Frutos, Hernández e Castelló, 2009; Grande e García, 2005; Mendoza, Orgambídez e Carrasco, 2010; Pérez e García, 2005; Pérez e López, 2006; Plaza, 2009; Polo e Frías, 2010; Roig, 2005; Sparrer, 2005; Valdés e De la Ballina, 2005) deron as súas instrucións e definicións sobre o turismo rural, pero non se conseguiu unha interpretación universal debido á falta de estudos que ter en conta. Estas cuestións poden chegar a dificultar a análise do turismo rural. No seguinte apartado recóllense as principais definicións desde o inicio do estudo deste fenómeno, nos anos noventa, buscando características comúns que axuden a clarificar este concepto.

Antes de centrarse no turismo rural en si, realízase unha introdución ao turismo de natureza, así como ao turismo de interior, o que permite ter unha perspectiva máis ampla e unha certa interrelación co turismo rural. Polo tanto, explícanse os tipos de turismo de natureza, dado que na parte empírica do traballo se van analizar posibles actividades complementarias, e xa que o turismo rural é esperable 
como aloxamento do turismo de natureza, en sentido contrario as actividades do turismo de natureza son as esperables como complementarias ao turismo rural.

En primeiro lugar, abórdase o concepto de turismo de natureza, xa que o turismo rural forma parte deste no sentido de que se atopa emprazado na contorna natural e é -ou potencialmente podería sero aloxamento habitual para os turistas que o practican.

A continuación, móstranse os principais tipos de turismo de natureza e detállase a súa interrelación, podendo ver así o papel que ocupa o turismo rural dentro daquel. Cando se fala de turismo de natureza está a mencionarse indirectamente o turismo activo, o turismo deportivo, o turismo de natureza, o ecoturismo e o turismo rural. Segundo a U.T.E. Antar-Ecotono (2004), pódese determinar que o turismo de natureza é un concepto extenso, que abarca a realización de actividades lúdicas, así como prácticas de análise e de entendemento do espazo natural a través da realización de prácticas deportivas con distintos graos de dificultade dentro do medio natural, non sendo necesarias as instalacións ou os equipamentos.

O turismo activo está directamente relacionado coa figura do turismo deportivo, sendo ambos os dous os máis restritivos en relación co termo xenérico de turismo de natureza. 0 nexo de unión destas dúas modalidades turísticas baséase na implicación da realización de actividades físicas e deportivas, comprendendo un maior ou menor grao de intensidade mediante o emprego do medio natural sen facer un mal uso del (U.T.E. Antar-Ecotono, 2004).

Por outra banda, Fullana e Ayuso (2002) completan esta clasificación sinalando que dentro das diferentes modalidades de turismo alternativo tamén se atopan o agroturismo, o turismo de aventura e o turismo cultural. Desagregando termos en función do seu obxectivo, o agroturismo baséase no aloxamento en entidades agrarias individualizadas, previo pagamento. 0 turismo de aventura en si enfócase á realización dalgún deporte nun espazo aberto e cun certo grao de risco. Pola súa banda, o turismo cultural céntrase na visita a recursos locais de carácter histórico, arquitectónico, artístico e étnico. 0 turismo alternativo é definido por Nel-Lo e Llanes (2015) como:

Aquel en que o individuo e o espazo se inclúen mutuamente. Mentres que o turismo de masas basea o seu valor en termos cuantitativos, o turismo alternativo basea o seu valor precisamente na calidade, en termos de goce do tempo de lecer, de promoción de actividades recreativas únicas, participativas. A diferenza é que o turismo de masas promove servizos, mentres que o turismo alternativo promove experiencias conscientes (p. 15).

Dentro deste marco vinculado ao turismo alternativo atópase o turismo de interior, dado que se trata dun antónimo do turismo de masas polo que pode aquel relacionarse co turismo rural, a pesar de certas diferenzas (Díez, 2012).

Diversos autores (Cànoves, 2008; Díez, 2012) afirman que todo aquel turismo oposto ao desenvolvido en zonas costeiras é turismo de interior, incluíndo tipoloxías como o natural, o urbano ou o cultural. Pola contra, o turismo rural é o máis semellante ao turismo de interior, ata o punto de consideralos practicamente sinónimos.

Outros autores (Díez, 2012) matizan esta diferenza entre o turismo de interior e o turismo rural, baseándose en que o turismo rural é un tipo de turismo dentro do turismo de interior. Con todo, o turismo de interior abarca máis tipoloxías de turismo, feito que Santos e Paül (2011) certifican.

Wilson, Fesenmaier, Fesenmaier e Van Es (2001) indican que o turismo rural é aquel desenvolvido no campo e que alberga unha oportunidade empresarial, é dicir, de negocio. Sparrer (2007) sinala que o turismo rural é aquel que se efectúa no ámbito rural. Melián e Camacho (2001) definen este tipo de turismo como aquelas prácticas de lecer ou recreo que utilizan como soporte o medio natural e como estrutura de apoio as comunidades rurais coa súa oferta de aloxamento, restauración e actividades complementarias.

O turismo rural neste caso comprende o extenso concepto de "turismo en espazo rural", e con iso a concepción do turismo de natureza, desenvolvéndose nun medio rural. Así mesmo, non se refire soa- 
mente á estancia en aloxamentos que cumpran con esta tipoloxía, senón que o seu concepto se basea na inclusión de actividades tradicionais e de prestacións doutros prototipos turísticos como o turismo activo (Frutos et al., 2009).

Outras clasificacións inclúen o turismo rural dentro das tipoloxías de turismo específico e complementario. Pódese definir o turismo específico como "aquel en el que la principal motivación del viaje está relacionada con los gustos, aficiones y características personales del turista" (Chirivella, Lorenzo Artiles e Redondo, 2004, p. 9). Polo que respecta ao turismo complementario, o concepto fai referencia a unha forma de facer turismo que, polo xeral, non é consumida de maneira exclusiva, senón que a realización da viaxe tamén está motivada por outros factores (Chirivella et al., 2004).

Con todo, o concepto de turismo rural é identificado por Pérez de las Heras (2004, p. 106) como "el conjunto de actividades turísticas que se desarrollan en contacto con la naturaleza, la vida en el campo, en pequeñas poblaciones rurales". Aclara, así mesmo, que para que se dea un turismo rural este debe exercerse baixo o alugueiro dun cuarto ou dunha casa inmersa na contorna rural ou a través de actividades que se executen nese medio. Pola contra, fronte a esta concepción ampla, na que non se establece unha interpretación exacta do termo, outros autores interpretan o turismo rural do seguinte modo:

- 0 turismo rural defínese como a prestación de servizos turísticos e vacacionais mediante prezo, realizados en centros de acollida situados no medio natural (Corrales, 1993).

- Conxunto de aloxamentos, instalacións e estruturas de lecer e recursos naturais centradas no espazo rural (Bote, 1987).

- Produto turístico que designa a modalidade de turismo onde a familia rural alberga os turistas e é a súa anfitrioa. É un turismo difuso e disperso, que comporta outras actividades, ou ben acompaña as vacacións rurais, ou ben constitúe a base do interese do turista (Sanchís e Olcina, 1995).

- 0 turismo rural é unha noción vasta que cobre non só o agroturismo (é dicir, o aloxamento ofrecido por un agricultor) senón, igualmente, toda actividade turística no espazo rural. Este tipo de turismo exerce unha certa atracción sobre o cidadán en busca de vacacións relaxadas no campo e podería, se fose máis coñecido, alcanzar maior auxe e contribuír a realizar o obxectivo dunha mellor reparación do turismo no espazo e no tempo (Comisión de las Comunidades Europeas, 1985).

- Aquelas edificacións situadas no medio rural que, polas súas especiais características de construción, localización e tipicidade, prestan servizos de aloxamento turístico mediante contraprestación económica (Lei de turismo de Galicia, 2008).

Polo tanto, pódese concluír indicando que o turismo rural é un tipo de turismo alternativo, afastado da masificación e que se desenvolve no interior do medio natural. Este turismo debe estar suxeito a unha retribución económica, obtida do arrendamento de vivendas/cuartos, ou de actividades no medio rural, que favorezan a poboación local e que se integren con ela.

\subsection{Características do turismo rural}

Para que un turismo rural se dea, García Henche (2005) fala dunha serie de atributos que conforman o produto de turismo rural, entre eles a natureza, a gastronomía, roteiros, aloxamento ou outros itinerarios.

Melián e Camacho (2001) indican que os elementos que favorecen que o turismo rural sexa unha alternativa factible e viable son diversos, pero que os que máis predominan son os seguintes: a procura doutro tipo de fonte de ingreso diferente á das actividades agrarias; o afán de empregar o tempo de lecer de maneira oposta aos convencionalismos; o contacto coa contorna local e natural; o apoio da Administración Pública na procura de alternativas que favorezan as poboacións rurais economicamente máis deprimidas; o interese pola potenciación de produtos turísticos en contacto co medio ambiente e 
afastados da concepción do modelo tradicional de sol e praia; e a interrelación do mercado entre a oferta e a demanda de produtos para o seu consumo turístico.

Do mesmo xeito, estas autoras determinan que a finalidade dos factores descritos teñen que ter correlación coas políticas que lles afectan tanto directa como indirectamente, resumíndose en catro puntos: rendibilidade social e económica para a poboación local; preservación do medio ambiente, valores culturais, artísticos e etnolóxicos; retroalimentación entre oferta e motivacións da demanda de turismo rural; e aposta por actividades sustentables no longo prazo.

Doutra banda, os obxectivos fundamentais para que un turismo rural se dea baixo o prisma da sustentabilidade, para Martínez e Solsona (2000, pp. 12-13), son os seguintes: a mellora das condicións de vida da poboación local; a contribución á reactivación económica das zonas deprimidas; a xeración de rendas complementarias; a incorporación da muller ao traballo remunerado; a estabilización da poboación local desde o punto de vista demográfico; o mantemento da actividade agropecuaria e artesanal; o mantemento ou repercusión do patrimonio arquitectónico tradicional; a conservación do medio físico; e o enriquecemento cultural da poboación local.

Pola súa vez, para que un turismo rural se execute deben darse unha serie de condicións (Melián e Camacho, 2001): lexislación apta ao modelo turístico de interior que integre directrices e que priorice os obxectivos; complementar e contrarrestar actividades turísticas puras con actividades convencionais; mellorar a calidade de vida dos habitantes do núcleo rural a través de retribución directa ou indirecta (emprego); potenciar a rehabilitación de inmobles xa asentados no territorio; e inducir á consideración polo medio natural, pola poboación local e pola súa cultura.

En resumo, o turismo rural é unha alternativa ao turismo de masas que debe asentarse no medio rural, axustarse ás normativas vixentes, interrelacionarse coa natureza, co patrimonio, coa cultura e coa poboación local, conseguindo como resultado a sustentabilidade no medio/longo prazo, así como ser beneficioso directa ou indirectamente para a economía local.

\subsection{Vantaxes e inconvenientes do turismo rural}

Wilson et al. (2001) determinan que os establecementos de actividades turísticas ou agrarias situados na contorna rural e cun escaso nivel de aloxamento favorecen outros mecanismos de desenvolvemento no rural, ao requirir pouco investimento económico. Polo tanto, é máis sinxelo establecer outras tácticas para o desenvolvemento na contorna rural como o rendemento no nivel industrial. Esta produción pode ser desenvolvida localmente, mediante pemes situadas na contorna, sen necesidade de empresas foráneas, coa colaboración do goberno local. Dese modo, o turismo forma parte complementaria dos ingresos nas explotacións agrarias, proporcionando beneficios ás empresas de modo directo e indirecto.

Melián e Camacho (2001, pp. 872-873) redactan textualmente que os principais beneficios que proporciona o turismo rural son os seguintes:

- Favorece o contacto do habitante urbano coas actividades habituais do habitante do medio rural, potenciando o seu aprecio na medida en que as coñeza.

- Posibilita un diálogo, unha interrelación entre dúas formas culturais distintas (o habitante urbano e o do campo) a través de experiencias e coñecementos.

- Contribúe a que os habitantes do medio rural se identifiquen e estean orgullosos do seu pobo e da súa contorna, superando certos complexos de inferioridade.

- Permite vincular a poboación e, en consecuencia, evita a emigración sobre todo do colectivo dos máis novos, o máis propenso a esta.

- Mellora o nivel de vida dos habitantes do núcleo de poboación rural ao suplementar os seus ingresos, podendo ser estes directos (a través da hostalaría ou da restauración) ou indirectos (mediante o desenvolvemento da construción, servizos, tendas...). Tamén achega novos postos de traballo: gardas, guías..., co que se evita o despoboamento e o avellentamento da poboación. 
- Posibilita a repercusión de certos produtos artesáns, o mantemento de oficios tradicionais, así como do patrimonio inmoble, popular e histórico-cultural.

- Mellora a contorna ambiental, aínda que a primeira vista poida parecer contraditorio, xa que o turista rural accede a un medio, a un campo, no que se vive e se respira tradición, polo que as autoridades e os propios habitantes do medio rural teñen que ser capaces de manter as condicións que atraen o turista, o que axuda de forma clara á súa conservación.

É dicir, favorece a economía local e, polo tanto, a riqueza que se xera en todas as formas; repártese na comunidade, polo que o nivel de vida/benestar social mellora. Crea para o turista unha visión/experiencia oposta á vida en contornas urbanas. Revalorízase o territorio e foméntase o sentimento de identidade (orgullo) cara a el, evitando a emigración cara a outros destinos, e auméntase a preservación polo medio natural.

Do mesmo xeito que o turismo rural proporciona vantaxes, tamén implica certos inconvenientes. Neste apartado móstranse os impactos negativos que pode ter o turismo rural, como os descritos por Melián e Camacho (2001, pp. 873-874):

- O posible esgotamento ou o uso indebido dos recursos básicos, e en particular da auga, polo aumento do seu consumo, por exemplo, en piscinas ou xardíns.

- A aparición de lixos ou doutros desperdicios en áreas dificilmente controlables.

- $O$ incremento da contaminación de augas, tamén da atmosfera e mesmo a aparición de niveis de contaminación acústica.

- Os danos ao chan como consecuencia do tránsito continuado de persoas e medios de transporte: por exemplo, a redución da cuberta vexetal e o cambio nas comunidades florísticas, en particular o predominio das especies nitrófilas debido á vertedura de materia orgánica; a desaparición das capas fértiles superiores do chan; a compactación do terreo e o desenvolvemento dos fenómenos erosivos, así como a súa contaminación xeral.

- Os danos directos a especies vexetais e cultivos, tales como a redución brusca e mesmo a desaparición de certas especies vexetais por recoleccións abusivas, roturas de ramas, destrución de cultivos, e espolio en regadíos e árbores froiteiras, sen esquecer a redución das áreas naturais e agrícolas como consecuencia do incremento das construcións e das obras de infraestrutura e equipamento.

- Os danos ás especies animais, principalmente pola fuxida dos máis sensibles e polo aumento da presenza de especies oportunistas, sobre todo por graves danos nos períodos de celo, posta e cría dos inmaturos que provocan fracasos na reprodución tras o abandono da área de cría polos proxenitores, e mesmo a matanza dalgúns animais.

- O incremento potencial do risco de incendios e da presión ambiental xeral en paraxes naturais de especial valor.

- As interferencias co modo de vida tradicional, a perda de valores culturais e etnolóxicos, a banalización da cultura propia, producíndose, polo tanto, unha invasión de modos, gustos e costumes externos.

- A especulación e encarecemento da vida, coas graves repercusións que isto pode ocasionar sobre os propios habitantes da zona, mentres que os beneficiados son só uns poucos e, mesmo, ás veces alleos ao lugar, así como a detracción de recursos económicos cara a outros sectores.

Polo tanto, existen certos riscos de impactos negativos que se poderían xerar, como o esgotamento de recursos escasos, a xeración elevada de residuos non orgánicos, a deterioración das capas máis superficiais de chan, os danos en flora e fauna, o aumento de risco de incendios, a contaminación no modo de vida da poboación local ou a especulación do territorio, polo que é preciso facer uso deste turismo de maneira responsable co fin de minimizar eses inconvenientes. 


\section{Oferta e demanda do turismo rural en España e Galicia}

As orixes do turismo rural están en Gran Bretaña (Sanchís e Olcina, 1995), a pesar de ser un país caracterizado pola industrialización e pola urbanización. Outros aseguran que Irlanda é o país pioneiro nesta materia á hora de promover este tipo de turismo.

Desde os anos 90 combináronse actividades agrícolas e turísticas en países europeos, co fin de diversificar a oferta (Barbieri e Mshenga 2008; Ilbery, Bowler, Clarck, Crockett e Shaw, 1998; Polovitz, Black e McCool, 2001).

Sanchís e Olcina (1995) indican que deben existir catro puntos clave na oferta de turismo rural, traducíndose como os seguintes: oferta de paquete de turismo rural para poder ser considerado adecuadamente como produto turístico; capacidade de combinación con dous tipos de turismo diferente: o de saúde e benestar, así como o turismo activo; homoxeneización da oferta e obtención de información desta co fin de acadar o seu mercado meta; e colaboración dos axentes gobernamentais tanto internacionais como locais para crear sinerxías e potenciar este tipo de turismo.

A continuación, resúmese a situación da oferta de turismo rural desde a década dos anos noventa nas comunidades autónomas españolas onde se desenvolve principalmente este tipo de turismo (Brunet e Alarcón, 2008; Cànoves, Herrera e Villarino, 2005; Sanchís e Olcina, 1995; Soláns e García, 2001; Yuste, 1994).

a) País Vasco: primeira Comunidade Autónoma en España en instaurar o turismo rural. Actualmente ofrece máis de 130 establecementos desta índole, cunha media de entre dous e seis cuartos por casa, sendo coordinadas a través dunha oficina encargada de distribuír o turismo rural nesta Comunidade. Conta con axudas e subvencións ofrecidas polo Goberno Vasco e polas Deputacións Forais para fomentar a restauración destes inmobles con fin turístico.

b) Comunidade Autónoma de Navarra: Comunidade Autónoma por excelencia en servizos de calidade e cun alto grao de profesionalidade, sendo totalmente imprescindible a cualificación para poder emprender a actividade. É estritamente necesario atoparse no ámbito rural, ofrecer como máximo ocupación para 14 persoas e ser unha vivenda autóctona para poder percibir financiamento autonómico. A casa tradicional navarra pode ofrecerse como aloxamento compartido ou de alugueiro.

c) Aragón: as casas rurais nesta rexión forman a Asociación Pirenaica do Turismo Rural (TURAL), sendo a súa marca de representación na Comunidade. Conta adicionalmente con axudas económicas da Deputación de Aragón para a adecuación ao uso turístico.

d) Cataluña: a denominada casa do "pagès" é a residencia tradicional catalá que a Generalitat de Cataluña busca incentivar para esquivar o despoboamento do ámbito rural cara a núcleos urbanos a través da xeración de emprego e mellorando dese modo a economía familiar dos habitantes das áreas rurais.

e) Baleares: en Mallorca existe unha asociación de 26 casas que empregan o "habitage" para distribuírse a través dunha central con excelentes contactos comerciais, conseguindo un alto nivel de ocupación ao longo de todo o ano.

f) Andalucía: os inicios da rede de turismo rural nesta Comunidade Autónoma xurdiron a través de individuos particulares que ofertaron aloxamento en vivendas familiares na contorna rural. Por mor diso, definíronse diversos tipos de oferta, como o casarío, o cámping casarío, cuartos en casas particulares, alugueiro de vivendas unifamiliares completas e albergues colectivos.

g) Canarias: o Goberno local do arquipélago busca a través do turismo rural crear un maior grao de desenvolvemento neste ámbito, desvinculando as illas do modelo turístico tradicional de sol e praia, co fin de dar a coñecer os recursos naturais autóctonos.

h) Galicia: favorecida polas subvencións da Xunta de Galicia ao turismo rural e aos balnearios, Galicia diferencia catro modalidades de hospedaxe: pazos-hospedaría, pazos-residencia, casas de aldea-residencia e casas de labranza. 
Seguindo co caso da Comunidade Autónoma galega, obxecto de estudo, Turgalicia no ano 2009 determina a seguinte tipoloxía de establecementos de turismo rural, de acordo co estipulado no Decreto 191/2004:

- Grupo A: comprende os pazos, castelos, mosteiros, casas grandes, casas reitorais e aqueloutras edificacións que polas súas singularidades características e valor arquitectónico sexan recoñecidas como tales polos órganos competentes da Comunidade Autónoma de Galicia.

- Grupo B: comprende as casas de aldea situadas no medio rural que pola súa antigüidade e características de construción respondan á tipicidade propia das casas rústicas galegas.

- Grupo C: comprende as casas de labranza, entendendo como tales as casas situadas no medio rural e con cuartos dedicados ao aloxamento de hóspedes, nas cales se desenvolvan actividades agropecuarias nas que poidan participar os clientes aloxados. Esta forma de turismo é definida como agroturismo.

- Grupo D: neste grupo intégranse as aldeas de turismo rural. Enténdese por aldea de turismo rural o conxunto de como mínimo tres casas situadas no mesmo núcleo rural, que sexan explotadas de forma integrada e que pertenzan ao mesmo titular. 0 conxunto de vivendas gardará entre si unha distancia máxima de 500 metros.

Abad (2003) para o período 1993-2000 advirte do grande incremento do grupo B. Feito reconfirmado por Martínez (2004), quen estima que no ano 2002 o 16\% (dun total de 58) corresponde ao grupo A. $065 \%$ da oferta turística nestes espazos no medio rural (235 casas de aldea) correspóndese ao grupo designado como B, o C conta cun 18,8\% (68 casas de labranza), sendo o 0,2\% restante asignado ao escaso grupo D.

O incremento deste grupo B foi determinante, e así se reflicte na recompilación realizada por Turgalicia no ano 2009 e resumida por Lois, Piñeira e Santomil (2009). A segmentación da distribución por categorías execútase do seguinte modo:

- Grupo A: correspóndese a unha cuarta parte (15\%) da oferta total, distribuído en 46 pazos, 24 casas grandes e 15 casas reitorais.

- Grupo B: concentra a maioría da oferta, cun total de 399 establecementos (70,6\%).

- Grupo C: dentro desta agrupación existen un total de 77 casas de labranza, representando o 13,6\% da oferta absoluta.

- Grupo D: grupo minoritario nesta segmentación, cun total de 2 aldeas rurais ( $0,8 \%$ da oferta total).

Con todo, os datos de Turgalicia no ano 2017 sinalan o descrito a continuación:

- Grupo A: conta cun total de 82 establecementos, repartidos en 18 casas grandes, 15 casas reitorais, 45 pazos e 4 denominados como outras edificacións, representando un 14,72\% do total da oferta.

- Grupo B: segue consolidándose como o grupo maioritario cun total de 407 casas de aldea, as cales se corresponden cun $73,07 \%$ da oferta.

- Grupo C: 63 casas de labranza, as cales se corresponden cun 11,31\% da oferta.

- Grupo D: grupo máis reducido que conta con 5 aldeas rurais $(0,9 \%$ da oferta total).

Configúrase así un total de 557 establecementos de turismo rural. De realizarmos unha comparativa da mesma fonte (Turgalicia) no período 2009-2017, pódese visualizar que a oferta sufriu pequenas alteracións (Táboa 1, Figura 1).

0 grupo A reduciuse en 3, o B incrementouse en 8, o C diminuíu en 14 casas de labranza e o grupo D aumentou en 3 aldeas rurais, resumíndose nunha diferenza negativa de 6 establecementos de turismo rural. 
Táboa 1. Comparativa entre a totalidade de establecementos de turismo rural no período 2009-2017

\begin{tabular}{cccc}
\hline Grupo & Ano 2009 & Ano 2017 & Diferenza \\
\hline A & 85 & 82 & -3 \\
B & 399 & 407 & 8 \\
C & 77 & 63 & -14 \\
D & 2 & 5 & 3 \\
TOTAL & 563 & 557 & -6 \\
\hline
\end{tabular}

Fonte: elaboración propia a partir de datos extraídos de Turgalicia $(2009,2017)$.

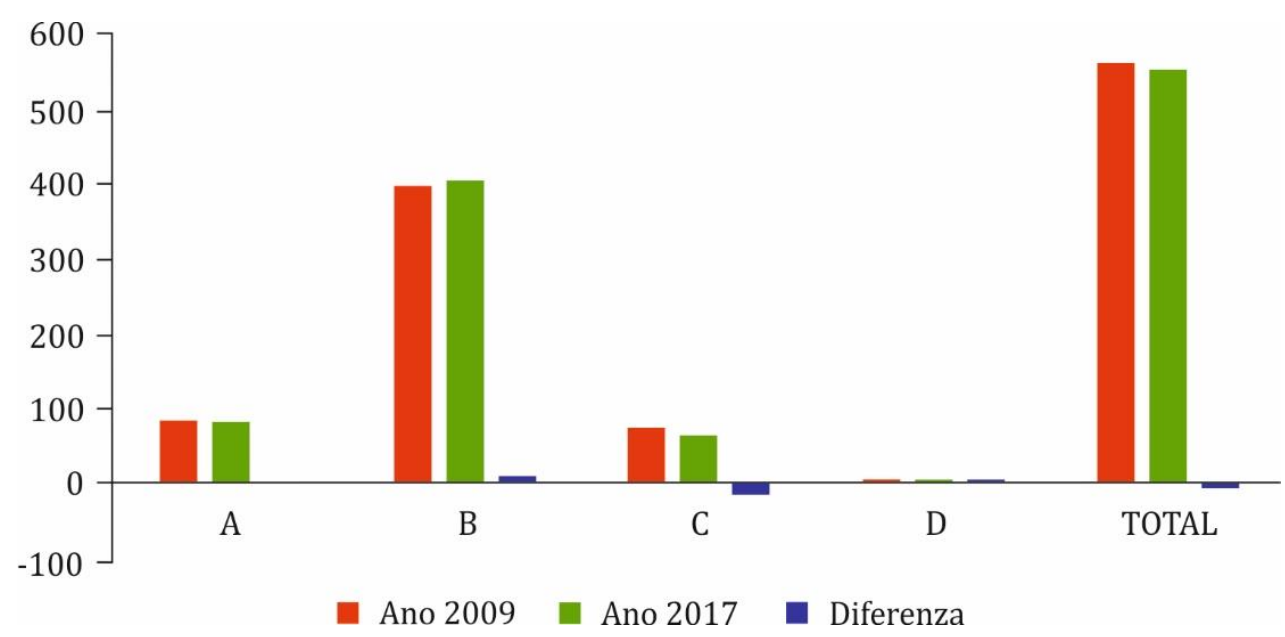

Figura 1. Comparativa dos establecementos de turismo rural 2009 vs. 2017. Fonte: elaboración propia a partir de datos extraídos de Turgalicia $(2009,2017)$.

En relación coa segmentación demográfica, extrapolando os datos de Turgalicia deste ano 2017 e ordenados de maior a menor, indícanse as provincias cun maior número de establecementos de carácter rural: Pontevedra: 29,80\% sobre o total; A Coruña: 29,27\% sobre o total; Lugo: $26,21 \%$ sobre o total; e Ourense: $14,72 \%$ sobre o total. Polo tanto, pódese observar que por grupo as provincias predominantes son as mencionadas a continuación:

- Grupo A: Ourense (32,93\%), Pontevedra (30,49\%), Lugo (19,51\%) e A Coruña (17,07\%).

- Grupo B: A Coruña (31,45\%), Pontevedra (29,73\%), Lugo (26,54\%) e Ourense $(12,28 \%)$.

- Grupo C: A Coruña (33,33\%), Pontevedra (31,75\%), Lugo $(31,75 \%)$ e Ourense $(3,17 \%)$.

- Grupo D: Ourense (60\%) e Lugo (40\%).

Adicionalmente, é fundamental recalcar a idea de que, coa colaboración gobernamental, se procede a unha homoxeneización da oferta co fin de establecer uns estándares onde o turismo rural, en combinación co turismo activo e de saúde, permita a posibilidade de formar paquetes para que se consolide a oferta ao longo do ano.

Polo que respecta á demanda, no comezo da actividade de turismo rural, englobado nunha Europa da segunda posguerra mundial, considerábase este tipo de turismo como unha maneira económica de gozar o tempo de lecer (Dewailly e Flament, 2000), pero co tempo estas pautas non se mantiveron estáticas, senón que o prezo medio subiu, o nivel adquisitivo dos demandantes foi maior, así como o seu nivel de información, requirindo polo tanto máis calidade (Echamendi, 2002). 
As motivacións da demanda en conxunto cos produtos turísticos son a imaxe dun destino, de acordo con Stabler (1990), formándose esta imaxe das relacións oferta vs. demanda dun espazo concreto. De acordo coas indicacións de Sanchís e Olcina (1995), no ano 1995 a afluencia de turistas na contorna natural e rural, atendendo ao desexo do contacto co medio ambiente, vese cada vez máis popularizada. Dentro deste marco, subdivídense tres segmentos de demanda: clase alta, que require servizos e establecementos de alta categoría e calidade; cliente novo, que non esixe unha excelente calidade, pero si unha relación calidade-prezo alcanzable e que cubra as súas necesidades; e turista senior (terceira idade), que busca un punto medio con respecto á clase alta e ao cliente novo.

A creación de espazos naturais protexidos, xa sexa por interese cultural, científico, educativo, recreativo ou turístico, favorecen a afluencia de turistas na contorna. Con todo, non se pode obviar o factor ecolóxico á hora de preservar a contorna.

Aínda que é certo que o turismo de sol e praia segue sendo o turismo máis estendido e consolidado en España ante a chegada de turistas internacionais, cada vez o turismo en espazos rurais está aumentado considerablemente ante esta afluencia de turistas estranxeiros.

Estudos máis recentes complementan a segmentación de Sanchís e Olcina (1995), pero en función da motivación (Martínez, 2004): física, cultural ou relixiosa e social.

Por outra banda, Lois et al. (2009) establecen unha listaxe de dez motivacións xeneralizadas que se dan no turismo rural, afirmando que calquera modificación ou omisión das calidades que nos indican depreciará a asociación que se ten coa contorna natural.

Echtner e Ritchie (1991) sinalan que cada individuo ten as súas propias motivacións, polo que a imaxe de destino en espazos rurais é totalmente subxectiva e persoal. Así e todo, Ugarte (2007) une unha listaxe de calidades xerais que se atopan relacionadas intrinsecamente coa imaxe de Galicia e, polo tanto, coa súa posición como destino turístico en dous niveis: o primeiro nivel asociado á boa preservación da contorna, a tranquilidade e a gastronomía autóctona de calidade, e o segundo bloque vinculado á sociabilidade dos habitantes e á riqueza patrimonial.

En conclusión, a pesar de que cada individuo ten as súas propias motivacións que repercuten na imaxe de destino que internamente xeran, o turista rural que practica este tipo de turismo en Galicia ten un nivel adquisitivo considerable, está ben informado e busca a calidade tanto nos servizos como nas instalacións, buscando en Galicia ese lugar onde desconectar da rutina, conectar coa vida local tanto gozando da gastronomía característica desta Comunidade Autónoma como socializando cos seus habitantes, así como gozando do seu patrimonio artístico ou arquitectónico.

\section{Metodoloxía da investigación cualitativa}

Tras realizar unha revisión teórica da literatura científica existente vinculada ao turismo rural, proponse unha técnica de tipo cualitativo para a obtención de datos primarios: a entrevista en profundidade (Báez, 2007). Este método está caracterizado por ser unha técnica de obtención de información directa, por ser flexible (realiza preguntas semiestruturadas) e por analizar a información obtida a través dun enfoque psicolóxico que recolle as crenzas, valores, desexos e actitudes das persoas. 0 total de entrevistas realizadas foi de 9 a expertos e responsables de casas rurais, polo que a información obtida serve de referencia para o territorio galego. Das 9 entrevistas realizadas, 4 foron na provincia de Pontevedra -primeira provincia galega en número de casas rurais-, 1 na Coruña (a pesar de estar na segunda posición do ránking de oferta), 2 en Lugo -terceira provincia no ránking- e, finalmente, 1 en Ourense. As entrevistas foron realizadas entre os meses de decembro de 2017 e xaneiro de 2018. Ademais, contouse coa colaboración dunha asociación turística galega como mentor nunha perspectiva xeneralizada.

A realización desta investigación xustifícase a partir do desexo de analizar a situación da Comunidade Autónoma galega como destino no que realizar turismo rural. A pesar de que Galicia posúe unha ampla variedade de casas rurais, a súa oferta parece non ser suficiente para crear unha maior afluencia. Por iso, o obxectivo principal deste estudo é coñecer o grao de desenvolvemento do turismo rural 
en Galicia e, como obxectivo secundario, matizar a oferta complementaria a este tipo de turismo máis solicitada, buscando así sinerxías con outras empresas do medio rural. Antes de comezar cun estudo cualitativo é importante saber o tipo de información que é interesante para a investigación. Para iso, establécense unha serie de obxectivos que engloban o que se pretende pescudar ao realizar as preguntas. A continuación, expomos eses obxectivos:

- Obxectivo 1. Determinar cal é o nivel de desenvolvemento da oferta rural en Galicia. Neste caso, considérase importante coñecer as actividades que ofrecen, en que medios, o nivel de profesionalidade dos seus traballadores, a seguridade no desenvolvemento desas actividades, a calidade no servizo, o grao de accesibilidade...

- Obxectivo 2. Investigar a demanda e estudar a súa interrelación coa oferta. Neste sentido é interesante saber cales son as súas motivacións, que actividades realizan...

- Obxectivo 3. Estudar a competitividade de Galicia respecto doutras Comunidades para así poder detectar e avaliar as principais debilidades e fortalezas do territorio galego.

- Obxectivo 4. Detectar oportunidades dentro do mercado actual e potencial.

- Obxectivo 5. Estudar a relación do turismo rural con outras actividades turísticas.

A continuación, recóllense os expertos que participaron nas entrevistas (Táboa 2).

Táboa 2. Persoas entrevistadas

\begin{tabular}{cl}
\hline Código & \multicolumn{1}{c}{ Experto } \\
\hline E1 & Representante asociación turística. \\
E2 & Xerente dun albergue (Pontevedra). \\
E3 & Propietario dunha casa rural (Pontevedra). \\
E4 & Encargado dunha casa rural (Pontevedra). \\
E5 & Xerente dunha casa rural (Pontevedra). \\
E6 & Encargado dunha casa rural (A Coruña). \\
E7 & Xerente de apartamentos turísticos (Lugo). \\
E8 & Propietario dunha casa rural (Lugo). \\
E9 & Xerente dunha casa rural (Ourense). \\
\hline
\end{tabular}

Fonte: elaboración propia.

\section{Resultados}

En relación co primeiro obxectivo, o cal se enfoca en determinar o nivel de desenvolvemento da oferta en Galicia, con actividades ofertadas (se é así, en que medios), nivel de profesionalidade no sector, seguridade, calidade do servizo e grao de accesibilidade, entre outras, con relación directa ás preguntas da entrevista 1 e 3, obtivéronse os seguintes resultados.

En referencia á primeira pregunta, 3 dos entrevistados (E3, E4 e E8) comentan que principalmente se segmentan en función da localización, é dicir, se se atopa a casa rural en territorio de costa ou de montaña. Acorde con esta localización, tanto o entrevistado E6 como o E8 indican que o paso do Camiño de Santiago é determinante para esta organización. 0 entrevistado E5 comenta que se segmenta por mancomunidades. Pola contra, afirma que non existe ningunha organización, sendo corroborado polo entrevistado E7, que non sabe como se clasifica.

Polo que respecta ao nivel de formación, practicamente todos os entrevistados están de acordo en que o nivel de formación no turismo rural é entre medio e escaso, incidindo nalgúns casos (E3 e E8) de que aos poucos se vai mellorando. Unicamente o entrevistado E5 está de acordo en que o nivel formativo é adecuado. Incidindo no caso, o entrevistado E3 comenta que en moitas ocasións se abusou das 
axudas do plan Leader, especialmente no caso de empresas familiares que aproveitaron as ditas axudas para rehabilitar as casas. Acorde á devandita achega, o entrevistado E4 tamén comenta que en moitos casos se trata de negocios familiares, que coñecen o sector desde pequenos e precisan de formación.

En canto aos ámbitos onde se debe incidir para unha mellora na formación, a resposta do entrevistado E8 é significativa, ao incidir en que existe un grupo de xente no sector que si que está a traballar ben, froito da experiencia, pero que tamén hai que mellorar e buscar fórmulas de mercadotecnia que axuden a iso.

O segundo obxectivo, no que se pretende investigar a demanda e estudar a súa interrelación coa oferta por mor das motivacións, actividades realizadas, etcétera, correspóndese coas preguntas 2, 4, 5 e 6 da entrevista. En resposta á pregunta 2, todos os entrevistados opinan que o turismo activo é a actividade complementaria que máis se oferta en Galicia, ademais do turismo gastronómico (E2, E3 e E4) e do enoturismo (E8 e E9), así como cultural, relacionado por exemplo cos certames de música ou coas visitas culturais (E4, E7, E8 e E9). Dentro deste grupo de opinións é importante resaltar unha matización, ao diferenciar o cliente en función da estacionalidade e da nacionalidade.

As actividades que máis se ofertan dentro da casa de turismo rural, e as que resultan máis positivas para os clientes, son as seguintes: rutas a cabalo (E3 e E5), rafting (E5) e sendeirismo (E5, E6, E7, E8 e E9).

Búscase ter un contacto directo co cliente a través de redes sociais para que o usuario poida ter unha vivencia integral e poder axustarse á demanda. Un dos entrevistados menciona que tentan ter contacto a través das redes sociais, especialmente Facebook, e si que é certo que incrementou o número de reservas vía online.

Á pregunta para coñecer a súa opinión de como se comportaría a demanda se se ofrecese unha oferta complementaria, un $75 \%$ dos entrevistados responde que consideran que a afluencia de turistas se incrementaría (E1, E4, E5, E7 e E9). Doutra banda, o resto das persoas consultadas consideran que é necesario ofrecer algo máis para que o usuario prolongue a estadía e teña unha experiencia máis vivencial (E2). 0 entrevistado E9 incide na importancia de crear empaquetados, feito co que outros entrevistados están de acordo.

A maioría dos entrevistados, no que toca á relación oferta vs. demanda, estima que existe un exceso de oferta (E1, E2, E5 e E9) ou de uso por parte da demanda estacional (E2 e E6). Só dous dos entrevistados consideran que a interrelación da oferta e da demanda é regular e equilibrada (E3 e E7, respectivamente), matizando o entrevistado E8 que considera que existe suficiente demanda pero que o déficit reside en non saber como enfocala.

Baseándose nos aspectos de maior relevancia no demandante para realizar este tipo de turismo e o destino preferente, a opinión dos entrevistados divídese en cinco bloques:

- Instalacións da casa rural en si: E1, E6 e E8.

- Contorna na que se atopa (paisaxe, proximidade a grandes núcleos de poboación, contacto coa natureza...): E2, E5 e E7.

- Factor meteorolóxico (clima): E7 e E9.

- Gastronomía: E2 e E3.

- Prezo: E2 e E9.

Tamén se incide no feito de que a través das redes sociais se pode chegar a un maior público obxectivo (E4), e á importancia dos accesos e da sinalización (E8).

Estudar a competitividade da Comunidade Autónoma galega con respecto a outras comunidades autónomas é o terceiro obxectivo. Co fin de poder detectar e avaliar as principais fontes de debilidades e fortalezas deste territorio, realizáronse as preguntas 7 e 8 da entrevista.

Ante a cuestión relativa a en que posto consideran que se atopa Galicia en relación co resto de comunidades autónomas que ofrecen turismo rural, agás o entrevistado E9, que afirma que non sabe, a totalidade dos expertos considera que se atopa nunha posición boa ou relativamente boa (E2, E3, E4, 
E5, E6 e E8). Tres integrantes opinan que, aínda que temos unha boa posición, nos atopamos por baixo do ránking con respecto a outras comunidades. E1 considera que nos atopamos na $4^{\underline{a}}$ ou na $5^{\underline{a}}$ posición, e E6 e E8 indican que na terceira, por debaixo de Madrid, Cataluña ou Valencia, no primeiro caso, e de Cataluña, Navarra ou Asturias, no segundo. Unicamente un entrevistado (E7) discrepa destas opinións e considera que Galicia se atopa por baixo da media española no que respecta a turismo rural.

Co fin de coñecer se Galicia é unha boa rival á hora de competir co resto de comunidades autónomas que ofertan turismo rural, hai diversidade de opinións. 0 entrevistado E6 comenta que estamos a crecer nesa competencia, e E9 recalca que se están facendo as cousas correctamente. Pola contra, tamén se incide na necesidade dun plan estratéxico e de oferta complementaria (E1), de supresión de trabas burocráticas (E7), así como do fomento no patrocinio desta realidade de turismo rural a través de plataformas ofimáticas, de Turismo de Galicia e de concursos entre viaxeiros (E4). Seguindo con esta oferta complementaria, un dos entrevistados incide na importancia do paso do Camiño de Santiago e da súa explotación a nivel turístico, así como da gastronomía local, feito que é compartido por E5 e por E2, que ademais subliña o factor marca Galicia. Discrepando das cuestións de competitividade atópase E8, quen considera que non é necesaria unha competencia entre comunidades autónomas.

0 penúltimo obxectivo fundaméntase en detectar oportunidades dentro do mercado actual e potencial, que se reflicte nas cuestións 9,10 e 11 da entrevista, das que se obtiveron os resultados que agora detallaremos coa finalidade de esclarecer os elementos que poderían ser empregados para xerar unha vantaxe competitiva: explotación de recursos naturais (E1, E2 e E6); prezos (E2); publicidade (E3); clima moderado (E6); e gastronomía (E6). As debilidades máis sinaladas son as seguintes: infraestrutura e comunicacións (E2, E7, E8 e E9); clima (E3 e E6); e exceso de oferta e pouca oferta complementaria (E5 e E1, respectivamente).

De igual modo, critícase que desde os organismos oficiais a política actual está a favorecer unicamente a promoción do turismo de alto standing, desatendendo a infraestrutura turística existente (E2); ademais da barreira idiomática, a desatención do estudo dos novos tipos de clientela (brecha xeracional), a ausencia de substitución xeracional (E8) ou a inestabilidade política (E4).

Con todo, no que concirne ás vantaxes, existe un acordo maioritario, pois exceptuando algúns matices, céntranse en: gastronomía (E1, E2, E3, E6, E8 e E9); paisaxe -contorna e patrimonio- (E1, E2, E8 e E9); hospitalidade (E1 e E8); e prezos adecuados (E2 e E9).

Con respecto aos cambios que se deben realizar para a adecuación á demanda actual, hai diversidade de puntos de vista. 0 entrevistado E1 comenta que debe ser cooperando con empresas que faciliten esa oferta complementaria, e dese modo xerar experiencias; experiencias que son compartidas polo entrevistado E8. Con todo, en liñas xerais a maior parte dos entrevistados comentan o lastre en termos de tecnoloxía e redes sociais, sinalando que se deberían actualizar máis e adiantarse así previamente (E4, E6, E8 e E9); recalcan, así mesmo, a participación dos touroperadores para poder adaptarse mellor ao nicho de mercado (E3).

En referencia ás oportunidades existentes no territorio galego, indícase que é un territorio con paisaxes únicas por descubrir (E1, E2 e E8). Un dos entrevistados, pola súa banda, comenta que cooperando con España se podería conseguir unha maior afluencia de turistas a Galicia. Con todo, con respecto a este punto, o entrevistado E4 expón a proposta de creación de museos ou rutas (ex. o volframio).

Para responder a pregunta sobre as tendencias futuras dentro do turismo rural, así como a adecuación das empresas a esta nova situación, existen respostas que realzan positivamente a situación actual, onde os entrevistados E4 e E6 indican que terá unha tendencia proveitosa, sempre que se manteña o "saber facer" como ata agora (E4). Doutra banda, o experto E8 incide en que cada vez máis viaxeiros complementan as actividades de maneira independente, polo que se desvirtúa a esencia. Con todo, moitos se atopan en sintonía, tanto nas tendencias como nos cambios que realizar para adaptarse aos novos públicos (millennials) e ás redes sociais (E1, E3, E4, E6 e E8). Ademais, coméntase (E2 e E8) que se deben aproveitar os recursos existentes, fomentar a aprendizaxe de idiomas estranxeiros (E6) para 
poder chegar ao nicho de mercado anglosaxón e crear especializacións/diferenciacións entre unha casa rural e outra (E4).

Finalmente, o último obxectivo consiste en estudar a relación do turismo rural con outro tipo de actividades turísticas, cuestionadas na pregunta 12. As respostas presentan múltiples opcións, desde os entrevistados que opinan que sería compatible con calquera tipo de turismo (E2), a través do turismo de aventura, o turismo sustentable, cultural, experiencial (E4), co turismo de vodas (E1), interrelacionándose con diversas empresas da contorna (E7), cultura e patrimonio de forma integral (E8), ata os que consideran que é complicado (E3).

A maiores, engadiuse un apartado extra (pregunta 13) para que o entrevistado puidese ofrecer calquera tipo de información adicional que cumpriría abordar. Aquí comentáronse aspectos como a mellora dun plan específico no marco do turismo rural ou críticas aos organismos públicos, aínda que tamén xorden críticas a organismos privados.

\section{Conclusións}

O obxectivo principal desta investigación é coñecer o grao de desenvolvemento do turismo rural en Galicia, así como a procura de sinerxías con outras empresas ou actividades aplicables ao medio rural, que permitan complementar e axustar a oferta de turismo rural de cara á demanda actual e potencial. Para iso, establécese un marco teórico sobre o que fundamentar o proxecto e, posteriormente, entrevistar expertos, propietarios e xerentes de casas de turismo rural, coa finalidade de detectar os nexos de unión nas preguntas establecidas, así como outro tipo de información relevante que permita responder as cuestións expostas ao longo da investigación.

En resposta aos subobxectivos establecidos, determínase que a segmentación da oferta no territorio galego non se atopa do todo precisa, aínda que pode derivarse en variantes como a localización (costa ou montaña), a proximidade ao Camiño de Santiago ou a mancomunidades. 0 nivel de formación con que gran parte dos propietarios e xestores de casas rurais, coas axudas do Plan Leader, e sen coñecementos e formación específica previa, estableceron este tipo de negocios familiares é medio.

En relación coa interrelación oferta/demanda, sinálanse dúas variantes. A primeira enfócase á desvinculación por parte do cliente da oferta complementaria por parte do aloxamento, é dicir, é o cliente o que decide as actividades que vai realizar, e a segunda mostra o caso contrario, onde o demandante busca actividades para realizar conxuntamente. Constan como as máis demandadas as actividades de turismo activo, turismo gastronómico e turismo cultural. A procura por parte de turistas nacionais e internacionais dun turismo que permita o contacto coa contorna, coa integración coa cultura local e familiar, son factores propios do turismo experiencial. Aspectos fundamentais para o demandante que realiza este tipo de turismo son as instalacións, a contorna, o clima, a gastronomía e o prezo. Acorde con estes parámetros de demanda, as actividades máis ofertadas polas casas rurais son as rutas a cabalo, o rafting e o sendeirismo, é dicir, a grandes liñas, o turismo activo. Ante a grande oferta, a estacionalidade do sector e a dificultade para enfocar a demanda, afírmase que a creación de empaquetados permitiría unha maior afluencia de fluxos turísticos. Adicionalmente, recálcase a mellora en accesos, a sinalización e un maior uso de redes sociais para adaptarse mellor ao mercado.

Respecto da competitividade da Comunidade Autónoma galega, determínase que se atopa nunha posición favorable ( 5 primeiros postos) con respecto a outras autonomías, sendo a súa principal competidora Cataluña. Establécense como principais debilidades de Galicia a falta dun plan estratéxico, a carencia de actividades complementarias adecuadas ao mercado, as trabas burocráticas, a escasa substitución xeracional ou a barreira idiomática. Con todo, as fortalezas sinaladas son a importancia do Camiño de Santiago, a paisaxe/contorna e a gastronomía autóctona como factor marca. Suxírese a colaboración entre comunidades autónomas e empresas de turismo complementario/touroperadores para ofertar un produto diferenciado, ademais dunha maior presenza en publicidade, tecnoloxía e redes sociais. 
Dentro das vantaxes competitivas actuais en Galicia pódense determinar a explotación dos recursos naturais que ofrece a contorna, o prezo, un clima moderado e o factor gastronómico, tendo como oportunidades a explotación do territorio galego aínda por descubrir e a posibilidade de crear novas rutas e museos. As tendencias futuras nesta rexión indican, por unha banda, que se debe manter o know how que se ten ata agora no que respecta á calidade de servizo, o fomento na implantación de cursos idiomáticos que permitan entrar en novos mercados e a adaptación ás novas xeracións (millennials). Así e todo, sinálase que parte dos viaxeiros seguirán complementando as súas propias vacacións.

A relación do turismo rural con outros tipos de turismo é intrínseca, sendo practicamente combinable con calquera tipo de turismo, entre os que destacan o turismo de aventura, o turismo activo, o turismo sustentable, o turismo cultural e patrimonial, o turismo experiencial, o turismo gastronómico e o turismo de vodas.

E para concluír, o turismo rural supón un gran potencial turístico para Galicia, facilmente combinable con outros tipos de actividades turísticas. Por iso, se se implementa un plan estratéxico con axuda de organismos públicos e con axentes turísticos, se se realizan accións de promoción e xestión de empaquetados e se se impulsan accións formativas que suplan a falta de coñecemento sobre o manexo de novas tecnoloxías e redes sociais, chegaríase a novos mercados e poderíase ofrecer unha oferta segmentada e diferenciada co fin de abarcar diferentes nichos de mercado.

\section{Bibliografía}

Abad, P. (2003). El turismo rural en Galicia. Revista Galega de Economía, 12(2), 1-25. Recuperado de http://www.usc.es/econo/RGE/Vol\%2012_2/Castelan/art1c.pdf

Báez, J. (2007). Investigación cualitativa. Madrid: ESIC.

Barbieri, C., e Mshenga, P. (2008). The role of firm and owner characteristics on the performance of agritourism firms. Sociologia Ruralis, 48(2), 166-183. DOI: https://doi.org/10.1111/j.1467-9523.2008.00450.x

Bote, G. (1987). Importancia de la demanda turística en el espacio rural y en España. Revista de Estudios Turísticos, 93, 79-92. Recuperado de https://dialnet.unirioja.es/servlet/articulo?codigo=2206614

Brunet, I., e Alarcón, A. (2008). Turismo rural en Cataluña. Estrategias empresariales. Revista Internacional de Sociología, 66(49), 141-165. DOI: https://doi.org/10.3989/ris.2008.i49.86

Campón, A., Baptista, H., e Hérnandez, J. M. (2009). El marketing relacional en el sector turístico. El caso del turismo rural: un enfoque teórico. En F. J. Cossío Silva (Coord.), Administrando en entornos inciertos: XXIII Congreso Anual AEDEM. Sevilla, 3-5 de junio de 2009. Madrid: ESIC. Recuperado de https://idus.us.es/xmlui/handle/11441/77758

Cànoves, G. (2008). Turismos de interior y turismo rural en Cataluña: los territorios soportes o protagonistas. En M. A. Troitiño, J. S. García e M. García (Coords.), Destinos turísticos: viejos problemas, ¿nuevas soluciones?: X Coloquio de Geografía del Turismo, Ocio y Recreación (pp. 373-404). Cuenca: Universidad de Castilla-La Mancha. Recuperado de https://dialnet.unirioja.es/servlet/articulo?codigo $=2728540$

Cànoves, G., Herrera, L., e Villarino, M. (2005). Turismo rural en España: paisajes y usuarios, nuevos usos y nuevas visiones. Cuadernos de Turismo, 15, 63-76. Recuperado de https://revistas.um.es/turismo/article/view/18511

Cebrián, F., e García, A. (2009). Dimensiones territoriales del turismo rural en Castilla-La Mancha. Serie Geográfica, 15, 79-91. Recuperado de https://dialnet.unirioja.es/servlet/articulo?codigo=3055895

Chicharro, E., e Galve, A. (2009). Alojamientos rurales en España: entre el crecimiento acelerado y el peligro de una sobredimensión. Serie Geográfica, 15, 125-137. Recuperado de https://dialnet.unirioja.es/servlet/articulo?codigo=3055905

Chirivella, M., Lorenzo, Y., Artiles, M. P., e Redondo, A. (2004). La formación de los técnicos y profesionales del turismo. En V Simposium Internacional sobre Educación Física, Deporte y Turismo Activo. Las Palmas de Gran Canaria, 1-3 de julio de 2004 (pp. 1-49). Las Palmas de Gran Canaria. Recuperado de https://docplayer.es/16251464-La-formacion-de-los-tecnicos-y-profesionales-del-turismo-activo-marianochirivella-yurena-lorenzo-ma-del-pino-artiles-y-alberto-redondo.html 
Comisión de las Comunidades Europeas. (1985). Programa de trabajo de la Comisión 1985. Presentación ante el Parlamento Europeo por el presidente Jacques Delors y contestación formulada al término del debate. Estrasburgo, 12 de marzo de 1985. Boletín de las Comunidades Europeas, Supl. 4/85. Luxemburgo, Luxemburgo: Oficina de las Publicaciones de las Comunidades Europeas.

Corrales, L. (1993). Apuntes para la definición y concepto de turismo rural. Ávila: Fundación Cultural Santa Teresa.

Correia, S. M., e Miranda, F. J. (2006). Calidad, satisfacción y fidelidad en el turismo rural: un análisis hispano-portugués. Papers de Turismo, 40, 49-66. Recuperado de http://www.papersdeturisme.gva.es/ojs/index.php/Papers/article/view/29/25

Crosby, A. (Coord.) (2009). Re-inventando el turismo rural, gestión y desarrollo. Barcelona: Laertes. Recuperado de https://dialnet.unirioja.es/servlet/libro?codigo $=378264$

Decreto 191/2004, de 29 de xullo, de establecementos de turismo rural. Diario Oficial de Galicia, No 154, de 10 de agosto de 2004, 11442-11453. Santiago de Compostela: Consellería de Cultura, Comunicación Social e Turismo. Recuperado de https://www.xunta.gal/dog/Publicados/2004/20040810/Anuncio172C2 es.pdf

Dewailly, J. M., e Flament, E. (2000). Le tourisme. Saint Germain du Puy, France: Sedes.

Díez, D. (2012). Los turismos de interior: un enfoque desde la dimensión de las modalidades turístico-recreativas. Documents d'Anàlisi Geogràfica, 58(3), 373-396. DOI: https://doi.org/10.5565/rev/dag.16

Echamendi, P. (2002). El turismo en los espacios rurales: el caso de Navarra. Propuestas para el futuro. En Jornada Autonómica de Navarra, Libro blanco de la agricultura y el desarrollo rural (pp. 1-20). Pamplona.

Echtner, C.M., e Ritchie, J. R. B. (1991). The meaning and measurement of destination image. The Journal of Tourism Studies, 2(2), 2-12. Recuperado de https://www.cabdirect.org/cabdirect/abstract/19921895612

Flores, D., e Barroso, M. (2011). La mujer en el turismo rural: un análisis comparativo de género en el Parque Natural Sierra de Aracena y Picos de Aroche (comarca noroccidental andaluza). Ager: Revista de Estudios sobre Despoblación y Desarrollo Rural, 10, 39-69. Recuperado de https://recyt.fecyt.es/index.php/AGER/article/view/12797

Frutos, L. M., Hernández, M. L., e Castelló, A. (2009). Desarrollo y turismo rural, una perspectiva sobre Aragón. Serie Geográfica, 15, 93-115. Recuperado de https://dialnet.unirioja.es/servlet/articulo?codigo=3055896

Fullana, P., e Ayuso, S. (2002). Turismo sostenible. Barcelona: Rubes. Recuperado de https://www.researchgate.net/publication/262209477 Turismo Sostenible

García, M., e De la Calle, M. (2006). Turismo en el medio rural, conformación y evolución de un sector productivo en plena transformación: el caso del Valle del Tiétar (Ávila). Cuadernos de Turismo, 17, 75-102. Recuperado de https://revistas.um.es/turismo/article/view/18281/17641

García Henche, B. (2005). Características diferenciales del producto turismo rural. Cuadernos de Turismo, 15, 113-114. Recuperado de http://www.redalyc.org/articulo.oa?id=39801507

García Henche, B. (2006). Marketing del turismo rural. Madrid: Pirámide.

Grande, I., e García, T. (2005). El diseño de la oferta de turismo rural: una aplicación a la Comunidad Foral de Navarra. Esic Market, 122, 99-118. Recuperado de https://dialnet.unirioja.es/servlet/articulo?codigo=1325277

Ilbery, B., Bowler, I., Clarck, G., Crockett, A., e Shaw, A. (1998). Farm-based tourism as an alternative farm enterprise: A case study from the Northern Pennines, England. Regional Studies, 32, 355-364. DOI: https://doi.org/10.1080/00343409850117816

Lei 14/2008, de 3 de decembro, de turismo de Galicia. Diario Oficial de Galicia, № . 246, de 19 de decembro de 2008, 22642-22665. Santiago de Compostela: Xunta de Galicia, Presidencia. Recuperado de https://www.xunta.gal/dog/Publicados/2008/20081219/Anuncio4C742 es.html

Lois, R. C., Piñeira, M. J., e Santomil, D. (2009). Imaxe e oferta no medio rural de Galicia. Revista Galega de Economía, 18(2), 71-90. Recuperado de http://www.usc.es/econo/RGE/Vol18 2/galego/art4g.pdf

López, F., Marchena, M. J., Antón, S., Vera, J. F. (Coords.), e Vila, J. (Pr.) (1997). Análisis territorial del turismo. Barcelona: Ariel.

Martínez, F. (2004). Turismo rural en Galicia. Contribuciones al desarrollo sostenible. Santiago de Compostela: Consellería de Cultura, Comunicación Social e Turismo, Dirección Xeral de Turismo. Recuperado de https://dialnet.unirioja.es/servlet/libro?codigo $=621613$

Martínez, A. S., e Ramón, F. (2011). Estudio comparativo de empresas de turismo de aventura de la provincia de Valencia. Gran Tour: Revista de Investigaciones Turísticas, 3, 51-68.

Martínez, J. F., e Solsona, J. (2000). Alojamiento turístico rural. Gestión y comercialización. Madrid: Síntesis. Recuperado de https://dialnet.unirioja.es/servlet/libro?codigo=222789

Melián, A., e Camacho, C. (2001). El turismo rural. Motivaciones y repercusiones. Agricultura. Revista Agropecuaria y Ganadera, 834, 871-874. Recuperado de https://www.mapa.gob.es/ministerio/pags/biblioteca/revistas/pdf Agri/Agri 2001834871 874.pdf 
Mendoza, M. I., Orgambídez, A., e Carrasco, A. (2010). Orientación a la calidad total, satisfacción laboral, comunicación y compromiso en establecimientos de turismo rural de la Sierra de Huelva. Pasos: Revista de Turismo y Patrimonio Cultural, 8(2), 351-361. DOI: https://doi.org/10.25145/i.pasos.2010.08.025

Nel-Lo, M., e Llanes, C. (2005). L'ecoturisme. Barcelona: UOC. Recuperado de https://dialnet.unirioja.es/servlet/libro?codigo=262524

Peñalver, M. (2004). El turismo activo como alternativa y complemento al modelo turístico en la Región de Murcia. Cuadernos de Turismo, 14,179-215. Recuperado de https://revistas.um.es/turismo/article/view/18561

Pérez de las Heras, M. (2004). Manual del turismo sostenible. Cómo conseguir un turismo social, económico y ambiental responsable. Madrid: Mundi Prensa Libros. Recuperado de https://dialnet.unirioja.es/servlet/libro?codigo=186314

Pérez, J. A., e García, Y. (2005). Turismo rural en Extremadura: el caso del “turismo paisano". Revista Española de Estudios Agrosociales y Pesqueros, 206, 87-110. Recuperado de https://dialnet.unirioja.es/servlet/articulo?codigo=2307599

Pérez, M., e López, E. (2006). La contribución del turismo a la diversificación de actividades en un espacio rural periférico. Análisis del impacto de la iniciativa Leader en Galicia. Revista de Estudios Agrosociales y Pesqueros, 206, 111-136. Recuperado de https://dialnet.unirioja.es/servlet/articulo?codigo=2307614

Plaza, J. I. (2009). Recursos territoriales para el turismo rural en las comarcas orientales de la Montaña Cantábrica. Serie Geográfica, 15, 51-65. Recuperado de https://dialnet.unirioja.es/servlet/articulo?codigo=3055886

Polo, A. I., e Frías, D. (2010). Collective strategies for rural tourism: The experience of networks in Spain. Journal of Tourism Comsumption and Practice, 2(1), 25-45. Recuperado de https://pearl.plymouth.ac.uk/handle/10026.1/11535

Polovitz, N., Black, R. J., e McCool, S. F. (2001). Agrotourism: Motivations behind farm/ranch business diversification. Journal of Travel Research, 40, 19-26. DOI: https://doi.org/10.1177/004728750104000104

Pulido, J. I., e Cárdenas, P. J. (2011). El turismo rural en España. Orientaciones estratégicas para una tipología aún en desarrollo. Boletín de la Asociación de Geógrafos Españoles, 56, 155-176. Recuperado de https://www.age-geografia.es/ojs/index.php/bage/article/viewFile/1348/1271

Roig, B. (2005). Estudio descriptivo de la demanda española de turismo en casas rurales. Revista Española de Estudios Agrosociales y Pesqueros, 207, 181-198. Recuperado de https://ageconsearch.umn.edu/record/166094?ln=en

Sanchís, A., e Olcina, L. (1995). El desarrollo del turismo rural y sus repercusiones. Papers de Turisme, 17, 89-101. Recuperado de https://dialnet.unirioja.es/servlet/articulo?codigo=4940379

Santos, X., e Paül, V. (2011). Contruíndo o turismo fluvial e de interior na Galiza. En R. Lois González e V. Paül (Eds.), Turismo fluvial e da natureza: un elemento de revitalización dos espazos rurais e do interior (pp. 17-34). A Coruña: IGEA.

Soláns, J. R., e García, E. (2001). Turismo rural en Aragón. Zaragoza: Universidad, Departamento de Economía y Dirección de Empresas.

Sparrer, M. (2005). Turismo no espazo rural e desenvolvemento. Estudo comparativo da provincia da Coruña e o Landkreis Wittmund. Santiago de Compostela: Xunta de Galicia, Dirección Xeral de Turismo.

Sparrer, M. (2007): Turismo no espazo rural e desenvolvemento. Santiago de Galicia: Xunta de Galicia, Dirección Xeral de Turismo.

Stabler, M. J. (1990). The image of destination regions: Theoretical and empirical aspects. En G. J. Ashworth e B. Goodall (Eds.), Marketing in the tourism industry: The promotion of destination regions (pp. 133-161). London, England: Routledge.

Turgalicia (2009, 2017). http://www.turismo.gal/polanifica-a-tua-viaxe/onde-aloxarse?langId es_ES.

U.T.E. Antar-Ecotono (2004). El turismo de naturaleza en España y su plan de impulso. Madrid: Ministerio de Industria, Turismo y Comercio.

Ugarte, X. (2007). Imagen y posicionamiento de Galicia como destino turístico a nivel nacional e internacional. (Tese de doutoramento). Santiago de Compostela: Universidade, Facultade de Psicoloxía. Recuperado de https://minerva.usc.es/xmlui/bitstream/handle/10347/2313/9788497508605 content.pdf?sequence=1\&is Allowed=y

Valdés, L. (2005). La calidad en turismo rural. El caso de las marcas de calidad regionales. Investigación y Marketing, 87, 43-48.

Valdés, L., e De la Ballina, F. J. (2005). La calidad en el turismo rural: el caso de las marcas de calidad regionales. Investigación y Marketing, 87, 43-48. DOI: https://doi.org/10.3989/ic.1975.v27.i269.2880 
Wilson, S., Fesenmaier, D. R., Fesenmaier, J., e Van Es, J. C. (2001). Factors for success in rural tourism development. Journal of Travel Research, 40(2), 132-138. DOI: https://doi.org/10.1177/004728750104000203

Yuste, F. (1994). Experiencias en el turismo rural: ofertas que ofrecen las comunidades autónomas. Vida Rural, 5, pp. 84-86. 